\title{
Identidades coletivas no Fórum Social Mundial ${ }^{*}$
}

\author{
Alexandre Carrieri ${ }^{l}$ \\ Daniel Calbino \\ Mariana M. Pereira de Souza \\ Universidade Federal de Minas Gerais
}

O presente trabalho teórico-empírico teve por objetivo compreender o processo de formação da identidade coletiva do Fórum Social Mundial (FSM). Entende-se que tal identidade, congrega uma série de outras identidades individuais e coletivas, estando o significado do FSM em constante construção e negociação. Ademais, a análise identitária deve se pautar pela conjuntura macrossocial no qual o FSM surge e se mantém. Para realizar a pesquisa, foram usados dados secundários longitudinais que formaram dois conjuntos discursivos distintos, referentes a duas instâncias formadoras da identidade do Fórum: o discurso oficial do FSM, e o discurso do sociólogo Boaventura de Sousa Santos. Os resultados, extraídos com base na Análise do Discurso (AD), demonstraram continuidades e rupturas identitárias, assim como contradições e consistências, revelando a complexidade da identidade coletiva do FSM e elementos da cultura política na contemporaneidade.

Palavras-chave: Identidades Coletivas - Fórum Social Mundial - Movimentos Sociais.

This theoretical and empirical work aimed at understanding the process of formation of collective identity of the World Social Forum (WSF). It is understood that such an identity, bringing together a number of other individual and collective identities, with the significance of the WSF in constant construction and negotiation. Furthermore, the analysis of identity should be guided by the overall macro in which the WSF comes and remains. To conduct the research, we used longitudinal secondary data sets that formed two distinct discourses, referring to two instances forming the identity of the Forum: the official discourse of the Forum, and the discourse of the sociologist Boaventura de Sousa Santos. The results, taken on the basis of Discourse Analysis (DA) showed continuities and ruptures of identity, as well as consistencies and contradictions, revealing the complexity of the collective identity of the WSF and elements of political culture in contemporary society.

Keywords: Collective Identities - World Social Forum - Social Movements.

\section{Introdução}

A partir da década de 1990, observa-se, nas chamadas novas democracias, A como o Brasil, uma modificação no caráter da participação social (PAULA, 2005; BURITY, 1999). Dentre as várias razões para a mudança na relação entre Estado e sociedade, podem ser listadas: processos de redemocratização,

\footnotetext{
* Collective identities in the World Social Forum

${ }^{1}$ Endereço para correspondências: Rua Flor de Fogo, 65, Apartamento 601, Bloco 3, Liberdade, Belo Horizonte, MG, 31270-217 (alexandre@cepead.face.ufmg.br, mariana_mayumi@yahoo.com.br e dcalbino@yahoo.com.br)
} 
elaboração da Constituição Brasileira de 1988, desregulamentação dos Estados Nacionais, implantação do liberalismo econômico, supressão das intervenções estatais referentes ao Bem-Estar Social e notável persistência de miséria, desigualdade e insatisfação. A partir desse quadro, Silva (2002) ressalta que a sociedade brasileira passou a vislumbrar novas possibilidades de expressão política, por meio de novos espaços, institucionalizados ou não, de participação social, dentre eles os movimentos sociais.

Os movimentos sociais para Touraine (1999) são os frutos de contradições que se globalizaram, e sendo atores coletivos que necessitam de inscrição na historia, de uma definição clara do adversário, de uma visão da totalidade do cenário que se inscrevem e de uma organização. Ou seja, trata-se de um fenômeno inerente aos processos de mudança no funcionamento da sociedade, em qualquer que seja a época. Assim se destacaram, na Antiguidade, movimentos de escravos e os religiosos. Na Baixa Idade Média, de camponeses e servos. Na Moderna, mercadores e religiosos. Na contemporânea, o movimento operário, e, com o passar do século XX, os "novos movimentos sociais", como o ecológico, o estudantil, o feminista, o sem-terra, dos direitos humanos. No Brasil esta trajetória também se manteve presente, iniciando ainda na fase colonial (Quilombos dos Palmares, Alfaiates, Inconfidência Mineira), no período do Império(Cabanagem, Sabinada, Revolução praieira), na primeira republica(revolta da vacina, revolta da chibata, revolução dos tenentes), no período populista movimentos Nacionalistas e Bairristas), no regime militar (movimentos estudantis, movimentos sindicais e populares urbanos), até aos períodos atuais (ecologismo, ONGs, cooperativismo popular, empresas ocupadas).

No que se refere aos movimentos sociais contemporâneos, estes se caracterizam pela facilidade de intercâmbio e comunicação de idéias. Isto possibilitou uma maior articulação em redes temáticas ou organizacionais, para que projetos políticos, espaços e linguagem sejam compartilhados. Em âmbito internacional, chama-se a atenção para o surgimento de redes de movimentos e Organizações Não-Governamentais (ONGs) internacionais, com atuação em vários países diferentes. Tal fato tem fundamentado a emergência do discurso sobre a formação de uma sociedade civil global, que questiona a identificação territorial e advoga certos temas que seriam globais - como meio ambiente, gênero, desenvolvimento local, segurança alimentar e monitoramento do sistema financeiro (SILVA, 2002).

Uma das principais funções dos movimentos sociais contemporâneos seria a formação de um ator coletivo, capaz de conferir notoriedade a determinada temática. "Ator coletivo que não pressupõe a dissolução das identidades envolvidas, mas possibilita a construção de consensos e formulação de ações comuns a partir de uma interação comunicativa" (SILVA, 2002; p. 145). 
Hardy e colaboradores (2005; p. 61) parecem concordar com Silva (2002) em relação à importância da comunicação para a formação de identificações coletivas: "[...] processos discursivos produzem identidades coletivas, que levam a várias formas de ação coletiva, potencialmente incluindo colaboração efetiva".

Oliveira (2007) destaca a importância das identidades coletivas na sociedade brasileira a partir da década de 1980. Contudo, o autor ressalta o caráter temporário das identidades dos sujeitos coletivos, como posições-de-sujeito situacionais, construídas por práticas discursivas e baseadas em algum interesse em comum. Isto porque os movimentos sociais são necessariamente heterogêneos (BARROS \& PAULA, 2008) e cada indivíduo constrói sua própria relação identificatória com o grupo. No caso do Fórum Social Mundial (FSM), pode-se afirmar que o interesse comum daqueles que participam é a resistência à globalização econômica hegemônica, por meio da proposta de valorização e expansão das alternativas econômicas do comércio solidário e justo, cujo objetivo principal seja o desenvolvimento humano sustentável, em vez da acumulação do lucro. Debaixo dessa ampla temática, articula-se uma variedade de posicionamentos e opiniões, o que caracteriza uma grande diversidade e heterogeneidade no interior do FSM.

Os Fóruns Temáticos surgem então como formas de integrar e articular a sociedade civil contemporânea, seja esta organizada em ONGs, movimentos sociais, partidos políticos, sindicatos, seja os próprios cidadãos interessados, técnicos, profissionais liberais, entre outros. Os fóruns não se constituem como instâncias representativas, ao menos este não é seu objetivo maior. São espaços de informalidade, horizontalidade e articulação de atores distintos, onde ocorreria uma atuação paralela ao poder público e não partidária. Neste sentido, os fóruns permitem uma troca mais livre de idéias e o desencadeamento de processos criativos, pois neles não há pressão para que decisões sejam tomadas (SILVA, 2002; PAULA, 2005).

Tendo em vista a conjuntura e os conceitos expostos, o artigo proposto teve como objetivo tratar da formação da(s) identidade(s) coletiva(s) no FSM. Dentro desse tema, buscou-se analisar a trajetória do fórum, as mudanças identificatórias ocorridas, como a saída do evento do Brasil e o não encontro de 2008. A partir da análise, tornou-se possível identificar as razões do surgimento do fórum na cidade brasileira de Porto Alegre, as identificações individuais e coletivas de participantes e movimentos sociais e os elementos de uma nova cultura política brasileira ou global. Para Oliveira (2007), o entendimento de tais questões é fundamental para se compreender o processo de emancipação política e social. 


\section{As identidades coletivas em movimentos sociais}

Os estudiosos dos movimentos sociais têm empregado o conceito de identidade coletiva para preencher lacunas deixadas pelas abordagens dominantes dos modelos de mobilização e processo político. Esses modelos aplicam perspectivas comportamentalistas, que concebem os protestantes como indivíduos desprovidos de razão, levados à ação pelo contágio das massas ou por pressões do sistema. A ênfase tradicional desses estudos estaria mais no "como" ocorre a mobilização, do que no "porque" de seu surgimento. Em resposta a essas lacunas, o estudo das identidades coletivas em movimentos sociais se faz interessante para ampliar a compreensão de questões não abordadas anteriormente (POLLETTA \& JASPER, 2001).

Entretanto, o termo identidade coletiva tem suas raízes em diversos conceitos sociológicos tradicionais, que vão desde a idéia de "consciência coletiva" de Durkheim até a questão da "consciência de classe" de Marx (HARDY et al., 2005). Devido à variedade conceitual, o termo identidade coletiva tem sido utilizado em ocasiões diversas, resultando em confusão teórica. Por exemplo, a identidade coletiva tem sido empregada para explicar muitas dimensões e dinâmicas diferentes em protestos sociais: a predominância de categorias sociais entre os participantes, as representações públicas das categorias sociais, as definições partilhadas entre os ativistas de suas posições, o caráter expressivo de toda ação, a solidariedade nos movimentos, fatores que motivam a participação, entre outros (POLLETA \& JASPER, 2001).

Para evitar a aplicação indiscriminada do conceito, Polletta e Jasper (2001) definem identidade coletiva como uma conexão cognitiva, moral e emocional do indivíduo com uma comunidade, categoria, prática ou instituição. É a percepção de status ou relação compartilhada, que pode ser imaginada simplesmente ou experienciada diretamente. A identidade coletiva é fluida e relacional, emergindo das interações com inúmeras audiências diferentes. Hardy e colaboradores (2005) sugerem que as identidades coletivas são produzidas discursivamente, por meio de conversações, que criam realidades comuns para os membros.

As identidades coletivas são expressas em materiais culturais, nomes, narrativas, símbolos, estilos verbais, etc. A identidade se diferencia da ideologia, pois ela necessariamente implica em sentimentos positivos em relação aos membros do grupo. O desafio analítico desse campo de estudos é identificar as circunstâncias nas quais operam diferentes relações entre interesse e identidade, estratégia e identidade e política e identidade. Tais circunstâncias incluem processos culturais e também estruturais (POLLETTA \& JASPER, 2001).

Estudos tradicionais sobre a tomada de decisão em grupos se baseiam na oposição entre identidade coletiva, como expressão do que é o grupo, 
e a estratégia, como instrumento. Contudo, estudos recentes têm relacionado identidade coletiva e estratégia de outras formas, rejeitando a visão tradicional. As próprias demandas identitárias podem ser vistas como estratégias de protesto ou as estratégias particulares podem ser associadas a identidades coletivas mais amplas. Assim, ativistas podem se associar a identidades coletivas estrategicamente e suas escolhas estratégicas ganham sentido em relação aos grupos com os quais os ativistas se identificam (POLLETTA\& JASPER, 2001).

A identidade coletiva do movimento e sua identidade tática geralmente coincidem, pois as organizações incorporam as formas de ação. Por outro lado, a compreensão de decisões táticas no interior de movimentos envolve a análise de numerosas identidades, com saliências variadas. Isto porque os movimentos são necessariamente heterogêneos e as pessoas não se integram ao coletivo como se não tivessem história própria (BARROS \& PAULA, 2008). Ativistas podem definir suas identidades de formas diferentes, dependendo da situação estratégica. Se eles representam o grupo em audiências públicas, eles podem se mostrar mais unidos e homogêneos, ao passo que, em uma reunião de membros, eles podem manifestar maiores discordâncias.

Burity (1999) afirma que o tema da identidade é relevante para o estudo dos movimentos da sociedade civil contemporânea, pois ele trata diretamente da ambivalência humana, entre demandas por igualdade e uniformidade, de um lado, e por exclusividade e liberdade, de outro. O estudo da identidade em seus múltiplos níveis, pessoal e coletivo, permite apreender a complexidade da formação de uma cultura política contemporânea, em um cenário de crescente apartidarismo e descrédito das instituições tradicionais.

Burity (1999) concebe a identidade coletiva como uma estratégia simbólica para lidar com o fluxo das experiências e sua ambivalência última, sendo indispensável a definição da concepção de um "nós" para o agir coletivo. Entretanto, tal definição deve estar em constante negociação, para se evitar que os sujeitos se apeguem à identidade coletiva como um dado imutável, natural e em constante ameaça de desvirtuamento e desrespeito por agentes externos. A questão da negociação da identidade é ressaltada nos novos movimentos sociais, como ONGs e fóruns. Da mesma forma, o chamado fundamentalismo das identidades também pode ser observado em movimentos mais conservadores. No primeiro caso, a tendência é o reconhecimento da pluralidade de identidades pessoais no interior do movimento, já no segundo, a tendência é a predominância de uma identidade comum para todos, suprimindo as diferenças.

De acordo com Polletta e Jasper (2001), ao contrário de movimentos sociais do passado, baseados em direitos civis e trabalhistas, que acarretavam participação de todos envolvidos, enquanto cidadãos, os movimentos contemporâneos, são formados por pessoas que normalmente já possuem todos os direitos de cidadãos normais, incluindo o direito de se mobilizar e de pressionar decisores políticos. 
Participantes nestes tipos de movimentos não possuem geralmente uma identidade imposta por sistemas políticos e legais, mas possuem liberdade para se engajar em reformulações criativas do que eles são. Neste sentido, a mudança apontada por Burity (1999) em relação à dinâmica das identidades coletivas nos movimentos do passado para os movimentos contemporâneos pode ter suas razões fundamentadas pela diferença nas reivindicações e nos processos de identificação e filiação dos indivíduos com o grupo.

\subsection{O processo de identificação e a formação da identidade social: por que participar?}

Para Polletta e Jasper (2001), a filiação a determinado movimento social, mesmo que não incorra em nenhum ganho material, não pode ser considerada uma atitude altruísta. Os autores afirmam que há uma conexão entre identidade coletiva e ação racional auto-orientada, pois a participação em determinado movimento social traz benefícios reputacionais e/ou realizadores para aqueles que compartilham da identidade coletiva. Nesse sentido, ativismo, para muitas pessoas, seria uma forma de construir um self desejado. Tal afirmação está alinhada à teoria social da identidade e da categorização social (TAJFEL, 1981).

Tajfel (1981) define identidade social como a parcela da auto-definição do indivíduo que deriva do conhecimento sobre sua filiação a grupos sociais e os significados emocionais e valorativos que essa filiação implica. Nesse sentido, o autor propõe uma perspectiva comparativa do conceito de identidade, $o$ que envolve diretamente a idéia de categorização. Os grupos sociais se tornam elementos de grande importância para a formação da identidade, tendo em vista que as categorizações ocorrem por meio da imagem que os grupos possuem perante seus membros e indivíduos externos. Para Tajfel (1981), um grupo se torna efetivamente um grupo quando se percebem características ou trajetórias comuns entre os membros, notadamente devido à existência de demais grupos distintos no ambiente. A definição do que seria um grupo social envolve três componentes: cognitivo, no sentido de se ter consciência da filiação ao grupo; avaliativo, no sentido de se ter noção da conotação positiva ou negativa do grupo; e emocional, no sentido de se criar sentimentos em relação ao grupo e às pessoas envolvidas. $\mathrm{O}$ autor, entretanto, ressalva que as identificações e as filiações dos indivíduos e dos grupos jamais são estáveis. Há uma relação dialética entre elementos do sistema social e as reflexões ou expressões das subjetividades dos membros.

A identificação social seria, portanto, a percepção de pertencimento ou de unidade com certo grupo social. A participação na maioria desses grupos é categórica, ou se é ou não é membro, por exemplo, os brasileiros, as mulheres, 
empregados da empresa X. Contudo, o grau de identificação do indivíduo com essas categorias pode variar. Para ocorrer identificação, não é necessário que o indivíduo despenda esforços na direção dos objetivos do grupo, ele necessita apenas se perceber alinhado psicologicamente com a trajetória do grupo, experienciando pessoalmente os sucessos e fracassos do mesmo. A identificação, além disso, se refere à identidade em termos das categorias sociais (eu sou). A identificação com um grupo, portanto, surge da necessidade de autodefinição, a partir das características do grupo (ASHFORTH \& MAEL, 1989).

Apesar de a identificação ser imprescindível para que um indivíduo decida espontaneamente participar de um movimento social, ela não é o único fator motivador, a partir da ótica da teoria social da identidade. Isto porque, no caso dos chamados grupos psicológicos, a identificação de um indivíduo com uma coletividade surge mesmo na ausência de coesão interpessoal, similaridade ou interações, e mesmo assim pode ter um impacto poderoso nas emoções e no comportamento. Exemplos de grupos psicológicos poderiam ser torcidas de futebol ou partidos políticos. Nesses casos, a identificação não requer necessariamente a interação entre membros do grupo, ou seja, um indivíduo pode se identificar com determinado movimento social, mas não efetivamente fazer parte dele (ASHFORTH \& MAEL, 1989).

Tajfel (1981) desenvolve então uma série de proposições que explicariam o engajamento dos indivíduos em movimentos sociais, para além da simples identificação. $\mathrm{O}$ autor define os movimentos sociais como formas de comportamento coletivo com o objetivo de promover ou resistir a mudanças na sociedade, consistindo em grandes grupos relativamente duradouros. Dessa forma, um movimento social seria fruto do esforço de um grande número de pessoas para resolver coletivamente determinado problema, o qual elas percebem ter em comum. $\mathrm{O}$ envolvimento do indivíduo em tais grupos estaria relacionado com dois contínuos importantes: comportamento interpessoal versus intergrupal e mobilidade social versus movimento social.

Em um dos extremos do primeiro contínuo, estaria o comportamento interpessoal puro - situação entre duas ou mais pessoas na qual a interação seria determinada unicamente por relacionamentos pessoais e pelas características exclusivamente individuais. Esse tipo de situação é uma abstração didática, sendo absurda na vida real. É impossível que não haja uma influência prévia mínima das categorizações sociais nas interações, mesmo no caso de amigos próximos e familiares. No outro extremo, por sua vez, estaria o comportamento intergrupal puro, caracterizado quando o indivíduo age como representante de seu grupo e enxerga o outro como integrante indiferenciado de um grupo externo. Tal situação é mais plausível na prática, sendo possível observar comportamento intergrupal quase puro, por exemplo, em guerras onde os soldados enxergam seus oponentes como inimigos todos iguais. 
Quando se aproxima do extremo integrupal, portanto, a tendência são comportamentos mais uniformes e previsíveis entre os membros e maior é a distinção entre os grupos externos.

O segundo contínuo está relacionado a dois tipos de crenças em relação à sociedade. Quando o indivíduo deseja mudar de grupo social e percebe que pode fazer isso enquanto indivíduo, sua percepção está próxima ao extremo da mobilidade social. Neste caso, o indivíduo acredita que os grupos sociais são flexíveis e permeáveis, sendo o movimento de um grupo para o outro livre e justo para todos. A crença na mobilidade social suscita, portanto, formas de comportamento interpessoal, aceitação da estrutura do sistema social corrente e resistência a mudanças nessa estrutura. Por outro lado, quando o indivíduo não está satisfeito com seu status social e, ao mesmo tempo, percebe que é impossível sair do seu grupo e melhorar suas condições sozinho, seu comportamento tenderá para o extremo do movimento social. Desta forma, ele tenderá a se comportar de forma intergrupal e advogará a mudança estrutural do sistema.

Portanto, o que leva o indivíduo a participar de um movimento social seria a insatisfação em relação a sua identidade vinculada a determinado grupo, aliada à idéia de que ele sozinho não pode mudar de grupo ou modificar a interpretação alheia a respeito do seu grupo. Na sociedade contemporânea ocidental, pode-se dizer que seriam predominantes comportamentos voltados às relações interpessoais e à mobilidade social, devido ao individualismo e ao descrédito em alternativas ao sistema capitalista. Desta forma, é possível afirmar que o engajamento em um movimento social exige uma mudança em termos da racionalidade a ser empregada no agir social e na construção da identidade.

\subsection{Mudança de racionalidade: quando participar?}

De acordo com Ramos (1989), Lima e colaboradores (2004) e Lacombe (2002), a principal esfera identificatória para os indivíduos na contemporaneidade é o trabalho, notadamente, em organizações econômicas. Lima e colaboradores (2004) ressaltam que, como o sujeito não constrói sua identidade a partir de si mesmo, mas em interação com o outro, no trabalho, o sujeito procura ser reconhecido pelo outro por o que ele faz e não por o que ele é. Isto porque, em organizações econômicas, geralmente, o indivíduo é valorizado pela sua capacidade de competir, pelos padrões de produtividade e qualidade de seu trabalho. Neste sentido, as identidades modernas são muitas vezes orientadas por uma racionalidade instrumental. Isto contribui para que o indivíduo se aliene na estrutura social e o impeça de perceber com clareza as verdadeiras fontes de seus sofrimentos. $\mathrm{O}$ indivíduo não vive mais de acordo com a realidade, na busca de sua auto-realização, passa "a viver e a acreditar em um imaginário construído a partir dessa realidade" (LIMA et al., 2004; p. 11). 
Como o trabalho não é capaz de satisfazer as necessidades de auto-realização dos indivíduos, a identificação e a filiação a movimentos sociais parecem uma saída para a construção de identidades substantivas. A partir dessas identidades, se tornaria possível a convivência em esferas não-econômicas da vida social, nas quais não predominam incentivos materiais de participação. Para Ramos (1989), somente nessas esferas é que seria possível o estabelecimento de relações afetivas autênticas entre os sujeitos. Esse autor defende que seria imprescindível para o sujeito a participação em esferas não-econômicas, sendo possível a aplicação da racionalidade substantiva, orientada para a afetividade e a satisfação dos desejos de auto-realização.

Nesse sentido, a participação em movimentos sociais estaria relacionada às necessidades intrínsecas dos indivíduos, na busca da construção de uma identidade autêntica e de verdadeiras relações afetivas interpessoais. Burity (1999) ressalta que a identidade é uma das questões centrais nos movimentos sociais da atualidade. A identidade torna-se um peso de que se deve desfazer ou algo precioso a defender. Segundo o autor, boa parte de participantes de ONGs, por exemplo, salientam a importância da autonomia relativa no processo de construção de identidades, seja individuais ou coletivas. Ademais, o engajamento efetivo de indivíduos em movimentos sociais, além da mera identificação, permite a criação de infra-estrutura institucional capaz de colocar membros em contato regular. Muitos atores coletivos como mulheres, idosos, gays, lésbicas e deficientes, inicialmente, não possuíam na sociedade tais espaços institucionalizados de convivência. Somente a organização dos movimentos sociais é que possibilitou o surgimento das redes de contatos entre tais coletividades, tornando-se assim lugares de identificação, de afirmação da autoestima, de troca de idéias, ou seja, de autenticidade nas relações (MINKOFF, 1997 apud POLLETTA \& JASPER, 2001).

Polletta e Jasper (2001) lembram que a identidade coletiva pode também ser vista como um resultado almejado pelos movimentos, sendo fruto dos processos de identificação e participação. Isto porque um dos objetivos primários de qualquer movimento é a mudança de identidades, posturas e comportamentos individuais. A participação geralmente transforma a vida dos ativistas, fazendo com que suas identidades pessoais fiquem marcadas mesmo após o fim do movimento.

\section{Percurso metodológico}

Como forma de investigar a(s) identidade(s) coletiva(s) presente(s) no Fórum Social Mundial, o presente estudo buscou analisar discursos vinculados ao fórum em duas instâncias diferentes: uma relacionada às identidades coletivas e uma relacionada à identidade individual. Primeiramente, 
foram selecionados textos coletivos referentes aos FSMs, ocorridos desde 2001, cartas assinadas pelos movimentos sociais participantes, metodologias empregadas em cada fórum, comunicados do comitê organizador e os temas norteadores de cada evento. Este conjunto de textos foi analisado com o intuito de revelar a projeção e a construção da identidade coletiva do FSM, bem como suas modificações ao longo do tempo.

Em seguida, foi analisado o discurso individual de um dos mais proeminentes participantes do FSM, o sociólogo português Boaventura de Sousa Santos. Boaventura é Professor Catedrático da Faculdade de Economia da Universidade de Coimbra, dentre outros títulos, que o fazem famoso entre acadêmicos e interessados nas áreas de ciência política, filosofia, sociologia e direito. Dentre suas principais obras, podem-se citar: "Um Discurso sobre as ciências" (1987), "O Fórum Social Mundial: manual de uso" (2005) e "Renovar a teoria crítica e reinventar a emancipação social" (2007).

Boaventura tem participado das edições do FSM desde 2001, por meio de palestras, debates e avaliações. Para análise de seu discurso, foram selecionados textos em que o sociólogo avalia cada edição do fórum, com exceção dos anos 2003, 2005 e 2007. Além disso, foi também analisado um texto do professor intitulado "O Movimento Democrático Transnacional", publicado na revista portuguesa Visão, em outubro de 2000. O objetivo da análise do discurso de Boaventura é identificar a percepção individual acerca do que seria o FSM, qual sua imagem, quais suas possibilidades de mudança social, o porquê de o enunciador participar desse movimento e quais seriam os elementos identificatórios envolvidos nessa participação.

Os textos para a pesquisa foram todos coletados na Internet, em sites oficiais do FSM, e de Boaventura, em sites de jornais eletrônicos e mídia independente. $\mathrm{O}$ intuito maior foi analisar discursos que são facilmente acessíveis ao público em geral, que funcionam como disseminadores e construtores de identidades e elementos identificatórios. De acordo com Hardy e colaboradores (2005), estudos discursivos sobre identidades coletivas se concentram no processo pelo qual tais identidades são criadas por meio de textos e na relação da identidade coletiva como objeto discursivo para padrões de ação. As identidades coletivas seriam produzidas por meio de conversações que constroem discursivamente "realidades" comuns para membros de diferentes grupos.

Neste sentido, acreditamos que o método de Analise de Discurso tornase bastante apropriado para a compreensão sobre as identidades coletivas. Segundo Mainguenaeau (2000; p. 13), a análise do discurso é: "a disciplina que, em vez de proceder a uma análise lingüistica do texto em si ou a uma análise sociológica ou psicológica de seu 'contexto', visa articular sua enunciação sobre um certo lugar social (grifos do autor)". Assim, 
percebe-se que uma das principais vantagens da utilização dessa técnica é a possibilidade de interpretação não apenas do que é dito, explicitado, mas sobretudo, trabalhar o que está por trás das falas, entendendo o que realmente os atores querem dizer e que não necessariamente é explicitado.

\section{O Fórum Social Mundial: origens, identidade e identidades}

O FSM surgiu em 2001, na cidade de Porto Alegre (RS), com o objetivo de oposição ao Fórum Econômico Mundial de Davos. Desde sua primeira edição, o evento foi capaz de congregar um grande número de entidades e movimentos, locais e internacionais. O FSM se caracteriza como um espaço aberto, democrático e receptivo, que não visa, ao contrário de outros fóruns, atuar como ator representativo junto ao poder público. De acordo com Silva (2002), os principais dilemas enfrentados pelos fóruns temáticos seriam a combinação de ação institucional e ação societal; e a combinação da manifestação das diferenças e formação de consenso. Nesse sentido, a postura não-representativa seria uma das formas adotadas pelo FSM para lidar com sua temática ampla e seus participantes heterogêneos. $\mathrm{O}$ fórum parece se empenhar mais em registrar idéias levantadas, promover a resistência e elencar alternativas para problemas relacionados a temáticas globais.

O FSM já ocorreu em oito edições, cinco delas no Brasil (2001, 2002, 2003, 2005 e 2009), uma na Índia (2004), uma simultaneamente em Mali, Venezuela e Paquistão (2006) e, a penúltima, no Quênia (2007). No ano de 2008, não houve encontro centralizado. Ao invés disto, foi proposta uma semana de mobilização e ação global durante o mês de janeiro. A não ocorrência do encontro do FSM nesse ano pode ter várias razões, dentre elas, a necessidade de repensar as temáticas e a atuação do fórum e de responder a críticas de que o FSM se tornara um evento apenas retórico e recuperado pelo capitalismo, sem relevância para a prática engajada e incapaz de promover mudanças estruturais. No ano de 2009, o FSM retornou ao Brasil, na cidade de Belém.

\subsection{A formação de uma identidade coletiva para o FSM}

Analisando o discurso do FSM ao longo dos seus nove anos de existência, é possível identificar continuidades e rupturas. De forma geral, o discurso é consistente e mantém os mesmos percursos semânticos (conjuntos de temas) ao longo do tempo: globalização, imperialismo, meioambiente, injustiça social e direitos humanos. Neste sentido, tratando inicialmente das continuidades, pode-se dizer que os eixos temáticos de todos os fóruns estão alinhados ao conteúdo da Carta de Princípios do FSM, documento redigido no ano de 2001 após a realização do primeiro FSM. 
Essa carta estabelece as diretrizes principais sobre o que seria o Fórum Social Mundial, estabelecendo sua continuidade e sendo referência para a construção de uma identidade coletiva para o Fórum.

$\mathrm{Na}$ Carta de Princípios, assim como em textos posteriores, o FSM é afirmado como local de encontro favorável à pluralidade de idéias, à diversidade, à construção de uma sociedade civil planetária, e contra o neoliberalismo, a globalização e a supressão de direitos humanos. Neste sentido, a seleção lexical dos textos, quando definem o FSM, varia entre as expressões: "espaço democrático e aberto de encontro", "processo permanente", "espaço plural e diversificado", "processo de caráter mundial", "reunião das melhores mentes do mundo", "trabalho teórico", "grande aliança", "movimento solidário global", "caminho para um mundo justo", "espaço de articulação". A partir da análise dessas expressões, destacam-se sentidos implícitos variados para o significado do FSM. Tais sentidos levam a algumas contradições identitárias, explicitadas em algumas passagens dos textos.

Primeiramente, o FSM ora é identificado como um espaço, simbólico e/ou concreto, com data e local marcados; ora é definido como processo ou movimento, dando a idéia de que o fórum não se esgota nos encontros anuais, sendo uma instituição aglutinadora perene dos movimentos sociais. Em segundo lugar, o FSM é às vezes definido por um caráter essencialmente pluralista e diverso, que não visa o consenso, mas sim a concessão de voz a alternativas variadas. Ao mesmo tempo, às vezes o FSM é colocado como o movimento dos movimentos, como uma instância de articulação capaz de um dia estabelecer um caminho para a mudança social alinhando os demais movimentos populares mundo a fora. Tal contradição é explicitada no fragmento abaixo:

Não se trata de centralizar as preocupações e ações
das organizações, redes e movimentos, mas de ex-
pandir, abrir espaço para a criatividade e iniciativa,
para que qualquer sensação de dispersão ou frag-
mentação em nosso trabalho seja desfeita. Desse
modo, os pontos de divergência e convergência
podem emergir mais claramente e dar dimensão mais
radical e força para a diversidade que nos caracte-
riza no FSM (Texto "Processo para 2004" -
www.forumsocialmundial.org.br).

Neste trecho, o enunciador explicita sua preocupação com a dispersão e fragmentação dos trabalhos no FSM e aponta para a necessidade de se ampliar as questões debatidas. Ao afirmar que as preocupações e ações dos movimentos participantes devem ser expandidas, o enunciador deixa entender que o FSM deveria dar ênfase a temas menos específicos e locais, para que desta forma as diferentes visões de mundo fossem evidenciadas e problematizadas. 
Destacam-se duas vozes, ou interdiscursos, que podem remeter a personagens implícitas: aqueles que se opõem à possível centralização e imposição de idéias no FSM e aqueles que criticam o evento pela dispersão e diversidade excessivas. Ao dialogar com tais vozes, o enunciador, enquanto representante do discurso oficial do FSM, procura persuadir o leitor que convergência e divergência são dois extremos passíveis de serem lidados.

Além da manutenção dos mesmos percursos semânticos ao longo do tempo, conforme já apontado, o discurso do FSM também mantém os mesmos personagens principais, que se agrupam de forma geral entre personagens coletivas e personagens individuais; e entre defensores, vitimas e vilões. A predominância é das personagens coletivas, principais no discurso. As defensoras coletivas seriam: movimentos, ONGs, redes sociais, fóruns. As vítimas coletivas seriam: povos, mulheres, trabalhadores, negros, indígenas, sociedade civil, empresas locais. Os vilões coletivos seriam: grandes corporações, elite global, Fundo Monetário Internacional (FMI), Banco Mundial, bancos regionais, Organização Mundial do Comércio (OMC), Organização do Tratado do Atlântico Norte (OTAN) e outras alianças militares. A transferência de responsabilidades entre as personagens coletivas é bastante clara, cabendo às vitimas se organizarem para se tornarem defensoras dos efeitos negativos das ações tomadas pelas vilãs. Já no caso das personagens individuais, algumas são citadas nominalmente e são, de forma geral: delegados dos movimentos, organizadores do FSM, chefes de estado, intelectuais, ativistas, dentre outros. Essas personagens recebem tratamento menos taxativo na maioria das vezes. As responsabilidades a elas transferidas variam de acordo com a ocasião. Dessa forma, o discurso, ao mesmo tempo em que faz generalizações por meio das personagens coletivas, evita transferir estereótipos para os indivíduos.

A respeito das rupturas identitárias do FSM, duas fases são passíveis de distinção: a formação de sua identidade, de 2001 a 2003, e a tentativa de sua legitimação, a partir de 2004. Na primeira fase, o FSM ocorre somente na cidade de Porto Alegre e recebe um número cada vez maior de participantes (de 20 mil em 2001 para 100 mil em 2003). Com isso, o discurso entoado pelo fórum ganha notoriedade mundial cada vez maior e se constrói a partir das temáticas explicitadas no trecho abaixo:

A partir das nossas discussões até o momento, é possível obter um certo consenso de que a ênfase no FSM 2001 foi criticar o neoliberalismo. No FSM 2002, as preocupações dominantes foram as alternativas. No Fórum de 2003, nós acrescentamos a isto idéias de estratégias e de caminhos para se chegar a "Outro Mundo Possível” (Texto "Processo para 2004" - www.forumsocialmundial.org.br) 


\title{
Hümanas
}

A partir do trecho, é possível inferir que a trajetória do FSM em suas três primeiras edições foi avançar dos protestos contra a ordem das coisas, para proposições de soluções. Neste sentido, a construção da identidade do Fórum seria de um espaço diferenciado, de criatividade e resistência. Apesar de atrair participantes de todo o mundo, o espaço era brasileiro e um dos seus pilares identitários era a oposição ao Fórum Econômico Mundial. Assim, a identidade do FSM se constrói propositalmente com uma carga simbólica forte, conforme explicitado por Francisco Whitaker, um de seus idealizadores:

\begin{abstract}
Esse encontro teria lugar, para se dar uma dimensão simbólica ao início dessa nova etapa, nos mesmos dias do encontro de Davos em 2001. [...] teria que ser no Terceiro Mundo - pelo seu efeito também simbólico - e o Brasil estava entre os países com melhores condições de acolher um Fórum desse tipo. Foi dele (Bernard Cassen) também a proposta de sediá-lo em Porto Alegre, capital de um Estado que vem se tornando cada vez mais conhecido em todo o mundo pelas suas experiências democráticas e de luta contra o neo-liberalismo (WHITAKER, 2000)
\end{abstract}

Neste trecho, está explícito o processo de formação da identidade do FSM e os significados simbólicos que se pretendia atrelar ao evento. Está implícito que a idéia de se criar o Fórum pertence a personagens individuais, uma explícita, Bernard Cassen, diretor do jornal francês Le Monde Diplomatique, e outra implícita, o próprio enunciador, o brasileiro Francisco Whitaker. Pelas nacionalidades dessas personagens, infere-se que desde o início o FSM parte de uma perspectiva internacional e transcultural.

A segunda fase identitária do FSM se inicia com a transferência do encontro para Mumbai, na Índia. Ainda se mantendo em um país em desenvolvimento, a organização do FSM também busca manter as diretrizes metodológicas dos Fóruns anteriores: oficinas, conferências, atividades auto-gestionadas pelos movimentos, acampamento dos jovens, debates, palestras e testemunhos. Entretanto, o Fórum na Índia simbolizou mudanças identitárias, por ocorrer em outro espaço geográfico, demandar a criação de um novo comitê organizador, trazer participantes novos e impedir antigos de participar e, conseqüentemente, trazer novas temáticas, conforme explicitado nos trechos abaixo:

Em 2004, pela primeira vez, o Fórum Social Mundial foi realizado fora do Brasil. A decisão foi tomada pelo Conselho Internacional como parte do 
processo de construção da internacionalização do FSM (Texto "Histórico do processo FSM" www.forumsocialmundial.org.br)

O FSM 2004 não é só uma oportunidade para se expandir a presença internacional ao Fórum, mas também para se explorar tematicamente os problemas em diferentes áreas do mundo (Texto "Metodologia do FSM 2004" - www.forumsocialmundial.org.br).

Infere-se, a partir da análise do discurso oficial do FSM, que o Fórum da Índia, apesar de ter atraído menos participantes e de sua maioria ser indiana, realmente foi capaz de aumentar o grau de internacionalização do processo e de trazer novas temáticas. No FSM seguinte, mesmo com o retorno a Porto Alegre, o número divulgado de países participantes aumentou de uma média de 120 para 155 e o número de participantes saltou para 155 mil. Além disso, a análise dos eixos temáticos de 2004 em diante permite concluir que eles se tornaram mais amplos, envolvendo temas típicos de outras partes do mundo: casteísmo, xenofobia, diversidade religiosa e étnica, fundamentalismo, militarismo e, mais recentemente, crise econômica mundial, entre outros.

A partir de 2004, ocorreram mais dois Fóruns fora do Brasil. Nota-se a crescente preocupação com a pertinência e organização das atividades do Fórum:

A construção da programação seguiu uma nova metodologia, que buscou ampliar a convergência, multiplicar os diálogos durante o evento e evitar a repetição desarticulada de atividades sobre o mesmo tema. [...] este fórum teve o desafio de ser mais propositivo, de avançar em agendas comuns e propor ações. Para isso, ele foi totalmente autogestionado (Cerimônia de Encerramento do FSM/2005 www.forumsocialmundial.org.br)

A sexta edição do Fórum Social Mundial foi policêntrica, ou seja, ocorreu de forma descentralizada, em diferentes lugares do mundo, em janeiro de 2006. [...] Este fórum tem a oportunidade e o desafio de ser o primeiro a aplicar a política de igualdade (Texto "Metodologia do FSM/2006"www.forumsocialmundial.org.br).

A necessidade de se estabelecer instruções gerais para se realizar um melhor trabalho de organização do FSM no futuro e de avaliá-lo posteriormente foi consensual. 


\title{
HUMANAS
}

[...] o processo do FSM deve facilitar essa diversidade e pluralismo, assegurando o acesso máximo para grupos marginalizados, garantindo acesso físico, financeiro e lingüístico, acesso a informação, espaço e assim por diante (Relatório do Comitê Internacional em Nairóbi, Janeiro/2007 www.forumsocialmundial.org.br).

Os Fóruns de 2005, 2006 e 2007 repetem o tema do aprimoramento metodológico. No primeiro trecho, os aspectos propositivos e convergentes da identidade do FSM são enfatizados. Infere-se que eventos autogestionados seriam a solução para articular melhor as atividades. Silencia-se, no entanto, o porquê da necessidade de se fazer um Fórum mais propositivo. O segundo trecho sinaliza para a possibilidade de um FSM baseado na política de igualdade, o que permite pressupor que os fóruns anteriores não se pautaram nessa política. Ao se dar em três locais, o acesso seria mais democrático. Por fim, o terceiro trecho aponta explicitamente para a necessidade de institucionalização dos procedimentos organizativos do FSM, por meio da expressão "instruções gerais". Ao se reportar o consenso de que a organização do FSM pode ser melhorada e que o acesso deve ser mais amplo aos grupos marginalizados, pressupõe-se que o FSM de 2007 ficou aquém das expectativas.

Outro traço importante que surge na segunda fase identitária do FSM é a ênfase na necessidade de realizar ações concretas. No ano de 2008, o encontro anual foi substituído por uma convocação a diversas ações de resistência e protestos pulverizadas ao redor do mundo.

\begin{abstract}
Conscientes da necessidade de construir nossa própria agenda e de aumentar o impacto dessas milhares de expressões e manifestações, nos comprometemos a reforçar a solidariedade e as convergências entre nossas lutas, campanhas, construções de alternativas e alianças.[...] Convidamos todas e todos que, dentro da diversidade que é nossa força, realizem criativamente nesta data ações, atividades, eventos e convergências sobre temas e em formatos que lhes sejam próprios (texto disponível no site www.wsf2008.net/pt-br).
\end{abstract}

A partir do trecho acima, destaca-se implicitamente que a realização de diversas ações solidárias pelo mundo traria maior impacto para os temas defendidos pelo FSM do que um evento em lugar e tempo determinados. Com esta nova metodologia, a identidade do Fórum se desvincula pela primeira vez dos encontros anuais. O enunciador, pelo uso da primeira pessoa do plural, 
define implicitamente o FSM como uma instância aglutinadora dos demais movimentos, capaz de preservar as identidades individuais e coletivas dos participantes e, ao mesmo tempo, capaz de alinhá-los em um nível estratégico mais amplo.

Finalmente, o FSM 2009 também caminha na direção da necessidade de proposição de alternativas, na promoção de mudanças e na convergência dos movimentos sociais pelo mundo.

Esta crise representa uma enorme ameaça para nossos povos, porém, também vemos nela uma nova oportunidade para promover alternativas populares ao sistema, avançando para uma mudança estrutural, cuja vigência e viabilidade se voltam incontestáveis. [...] A proposta que colocamos em discussão parte de: [...] definir planos de ação muito concretos, que apontem a um exercício prático de busca de soluções concretas para as necessidades cotidianas da vida da população (Carta dos Movimentos Sociais das Américas no FSM/2009www.fsm2009amazonia.org.br)

Neste trecho, a figura da crise, que remete implicitamente a problemas conjunturais em todo o mundo, se torna um problema central e compartilhado por todos e, nesse sentido, torna-se também um elemento capaz de alinhar os povos. Explicitamente, o enunciador aponta para a necessidade de mudanças estruturais, que se tornaram viáveis. Na segunda parte do trecho, contudo, o enunciador indica que tais mudanças ocorreriam a partir de atividades concretas na vida cotidiana. Tal afirmação entra em contradição interdiscursiva com o Trecho 1, na primeira fase, que defende a convergência por meio do foco no pensamento amplo. Tal diferença de postura pode sinalizar um dos aspectos de ruptura no discurso e na identidade do FSM em sua segunda fase.

\subsection{Elementos identitários relacionados ao FSM no discurso de Boaventura de Sousa Santos}

A análise do conjunto de textos assinados por Boaventura de Sousa Santos permite o levantamento de uma série de aspectos identitários do sociólogo e da identidade coletiva do FSM. Boaventura se auto-define explicitamente como "crítico de esquerda" e, mesmo antes do primeiro FSM acontecer, se coloca como defensor do chamado "movimento democrático transnacional", da "sociedade civil global" e de temas que constam na Carta de Princípios do FSM. Além disso, sua identificação com o FSM é explícita pelo uso da primeira pessoa do plural ao reportar os resultados dos Fóruns e pelo constante apoio e concordância com o discurso oficial do FSM. 


\section{HUMANAS}

O êxito do FSM esteve muito para além do que nele se decidiu. Esteve na afirmação e consolidação desta gigantesca rede de movimentos sociais e de organizações, uma rede que não se deixou intimidar pelos acontecimentos recentes e que, pelo contrário, colheu deles a urgência para prosseguir e ampliar a pressão organizada e pacífica contra aqueles que pretendem transformar o mundo num gigantesco condomínio fechado (Texto "FSM 2002: Um Fórum para durar" www.forumsocialmundial.org.br).

Neste trecho, Boaventura define explicitamente o FSM como uma rede de movimentos, construindo sua identidade coletiva para além do simples encontro, como uma entidade perene e inovadora capaz de organizar os demais movimentos. Essa é a identidade do FSM projetada consistentemente pelo discurso do sociólogo ao longo do tempo, que o caracteriza como "movimento dos movimentos", "globalização solidária dos povos", "espaço aberto global".

Dialecticamente, a sua fraqueza (a não discrimina-
ção entre soluções diversas) não pode ser separa-
da da sua força (a celebração da diversidade como
um valor em si mesma) e vice-versa. O FSM é tão
transitório como o nosso tempo e chama a atenção
para as possibilidades latentes desta transição.
Nisto reside o seu sucesso. (Texto "FSM 2008: A
Esquerda no Século XXI: as lições do Fórum Social
Mundial" - www.forumsocialmundial.org.br)

Nesta passagem, Boaventura se demonstra consciente da ambigüidade identitária "diversidade x convergência", identificada no discurso oficial do FSM. Está explícito que, para ele, essa característica é positiva e a razão para a existência bem sucedida do Fórum. Implicitamente, o autor contrapõe duas vozes, aquela que enxerga a pluralidade como fraqueza e aquela que a concebe como ponto forte do FSM. Infere-se que a primeira voz estaria ultrapassada, pois o "nosso tempo" é caracterizado por movimentos transitórios e menos propositivos. O sucesso do FSM, portanto, seria sua identidade coletiva cambiante.

Observa-se que, ao longo dos nove anos de Fórum, Boaventura refina suas idéias sobre a identidade coletiva do FSM, abandonando um pouco os temas da pluralidade para focar na necessidade de proposições e ações coletivas. Dessa forma, seu discurso segue a tendência do discurso oficial do FSM. O trecho abaixo é referente a um texto mais recente, sobre o FSM 2009: 
[...] o processo do FSM é hoje muito complexo e as reuniões bienais são apenas um dos seus pilares. [...] Para além delas, o processo do FSM é constituído por mais três pilares. O segundo pilar são as articulações mundiais entre movimentos temáticos que nos últimos anos têm vindo a definir acções e agendas políticas a levar a cabo tanto a nível nacional como regional e global. [...] O terceiro pilar do FSM em sentido amplo é constituído pela assembléia dos movimentos sociais. [...] é na assembléia que se transformam em decisões políticas muitas das reflexões realizadas nas reuniões do FSM e que por essa razão tenho vindo a defender uma maior articulação entre o FSM e a assembléia dos movimentos.

Neste fragmento, a identidade coletiva do FSM se constrói explicitamente sobre três pilares: as reuniões, as articulações mundiais dos movimentos e a assembléia dos movimentos. Está implícito no discurso de Boaventura que o FSM foi essencial para que houvesse maior diálogo e coordenação de atividades entre os movimentos sociais espalhados pelo mundo. Infere-se que os dois últimos pilares são conseqüências do primeiro. Há uma contradição no discurso quando este trata das assembléias, pois primeiramente elas são colocadas como componentes do FSM e depois o enunciador defende a aproximação do Fórum a elas, como se as assembléias fossem externas a ele. Nessa contradição, o FSM é definido como espaço de reflexão, sem decisões políticas.

Apesar de espelhar as ambigüidades e contradições da identidade coletiva do FSM, o discurso de Boaventura de Sousa Santos é alinhado ao discurso oficial do Fórum, indicando identificação do enunciador com o evento. As dificuldades em se definir o FSM podem residir na própria indefinição de sua identidade, ainda em (constante) construção.

\section{Conclusões}

O presente artigo buscou discutir questões identitárias coletivas suscitadas pelo surgimento do Fórum Social Mundial. Identificou-se que a identidade coletiva do Fórum foi construída com significados simbólicos, situando-o em espaço e tempo, mas tornando-o transcendente à dimensão concreta das reuniões. A dificuldade em se definir o FSM está pautada no ineditismo de seu formato e de sua proposta. As vozes detectadas na análise dos discursos parecem apontar para aqueles que esperam ações coletivas convergentes e propostas concretas de mudanças e aqueles que esperam do Fórum um espaço de expressão das diversidades, de troca de idéias, no qual não se chegue necessariamente a conclusões e consensos. 


\section{HUMANAS}

A análise das trajetórias do discurso oficial do FSM e do discurso de Boaventura explicita a tensão entre tais vozes e buscam construir discursivamente uma identidade para o Fórum capaz de conciliá-las. Entretanto, observase que recentemente ambos discursos têm reforçado a necessidade de tornar o FSM mais propositivo, alinhando as identidades e movimentos diversos que as reuniões atraem em prol de lutas conjuntas e coordenadas. Outra tendência identificada pela análise dos discursos é de se conceber o Fórum como algo que vai além dos encontros periódicos, sendo este um processo perene.

A experiência bem sucedida do FSM seria fruto de uma nova cultura política, que emerge da percepção de causas globais para os problemas locais; da liberdade de expressão e pressão para com governantes; da emergência de agendas globais de luta, em torno de temas como globalização, meio ambiente e neoliberalismo; da afirmação de identidades culturais e étnicas; e do discurso da integração da sociedade civil. Tais elementos culturais seriam tanto a causa como a conseqüência da identificação de indivíduos e de coletividades com o FSM. Conforme Polletta e Jasper (2001) observaram, as identidades coletivas podem ser um fator de motivação para participação em determinado movimento ou podem ser conseqüência dessa participação. A partir disso, afirma-se que, no caso do FSM, a identidade coletiva funciona para os dois momentos, tornando-se auto-reforçadora e em constante processo de negociação.

Apontam-se, todavia, inconsistências presentes nos discursos da "nova cultura política" e da "sociedade civil global". Primeiramente, a integração da sociedade civil ao redor do globo pressupõe possibilidade de formação de redes internacionais, troca de informações e mobilidade geográfica. A transferência do FSM para a Índia em 2004 demonstrou que ainda o acesso a tal mobilidade é restrito, o que impediu a participação de muitos e reduziu o número de pessoas no Fórum, notadamente as estrangeiras. Nesse sentido, ainda são grandes as barreiras de se fazer um evento global de acesso democrático.

Uma outra questão a ser levantada, é a baixa participação da população marginalizada, o que se torna uma objeção à afirmação da existência da sociedade civil global. Como explicitado nos discursos, falta às camadas mais pobres condições objetivas para participação em movimentos sociais, como dinheiro, tempo e acesso à informação, e falta também condições subjetivas, como conscientização e formação política. Neste sentido, reforça-se a proposição de Tajfel (1981) a respeito do aspecto essencialmente identitário da participação em movimentos sociais que visem mudanças estruturais na sociedade. O indivíduo somente irá se engajar em tais movimentos se estiver insatisfeito com sua identidade social e perceber que tal condição não será alterada por meio de ações interpessoais. Ou seja, mais do que insatisfação com condições materiais, o indivíduo deve estar à procura de uma mudança de caráter subjetivo, o que envolve necessariamente uma mudança de padrões de racionalidade. 
A ampla participação de intelectuais no FSM, como Boaventura, ilustra a busca por vínculos identitários a movimentos de mudança social, mais do que a necessidade concreta dessa mudança.

Desta maneira constatou-se o caráter instável e em constante construção da identidade coletiva do FSM. Esta última teria sido concebida, em um primeiro momento, por seus idealizadores de forma simbólica e, posteriormente, reconstruída pelas várias vozes em interação interdiscursiva. Os sujeitos que participam e integram a identidade coletiva do Fórum detêm o poder de reafirmar ou negar os significados atrelados a essa identidade. Isto dependerá tanto da suas próprias estratégias identitárias, quanto do contexto em que os indivíduos entoam seus enunciados (para agentes externos ou internos).

\section{Referências bibliográficas}

ASHFORTH, B. \& MAEL, F., Social identity theory and the organization. Academy of Management Review, 14(1): 20-39, 1989.

BARROS, A.N.; PAULA, A.P.P. Organizações sociais e projetos políticos: contribuições gramscianas para a discussão. III Encontro de administração pública e governança (Anais eletrônicos). Salvador: ANPAD, 2008.

BRASIL, F.P.D. Sociedade civil, espaços públicos e ação coletiva: reconstruções da agenda das políticas urbanas no Brasil dos anos 90. In: F.P.D. Brasil (Org.). Espaços públicos, participação cidadã e renovação nas políticas urbanas locais nos anos 90. Belo Horizonte: UFMG/FAFICH, 2004.

BURITY, J.A. Identidade e cidadania: a cultura cívica no contexto de uma nova relação entre sociedade civil, indivíduos e estado. Cadernos de Estudos Sociais, 15(2): Julho-Dezembro, 1999.

HARDY, C; LAWRENCE, T.B. \& GRANT, D. Discourse and collaboration: the role of conversations and collective identity. Academy of Management Review, 30(1): 58-77, 2005.

LACOMBE, B.B. A relação indivíduo-organização: é possível não se identificar com a organização? Encontro de Estudos Organizacionais. Recife: PROPAD/UFPE, ANPAD, 2002.

LIMA, S.M.M.; HOPFER, K.R. \& SOUZA-LIMA, J.E. Complementaridade entre racionalidades na construção da identidade profissional. RAE-Eletrônica, 3(2): Julho-Dezembro, 2004.

MAINGUENEAU, D. Termos-chave da análise do discurso. Belo Horizonte: UFMG, 2000 


\section{HUMANAS}

OLIVEIRA, F.M. Cultura política e construção de identidades coletivas de sujeitos sociais. XII Congresso Brasileiro de Sociologia (anais eletrônicos). Recife: UFPE, 2007

PAULA, A.P.P. Por uma nova gestão pública. Rio de Janeiro: Editora da FGV, 2005.

POLLETTA, F. \& JASPER, J.M. Collective identity and social movements. Annual Review of Sociology, 27, 2001.

RAMOS, A.G. A nova ciência das organizações: uma reconstrução da riqueza das nações. $2^{\text {a }}$ Edição. Rio de Janeiro: Editora da FGV, 1989.

SILVA, C.A. Os fóruns temáticos da sociedade civil: um estudo sobre o Fórum Nacional de Reforma Urbana. In: E. Dagnino (Org.). Sociedade civil e espaços públicos no Brasil. São Paulo: Editora Paz e Terra, 2002.

TAJFEL, H. Human groups and social categories. Cambridge: Cambridge University Press, 1981.

TOURAINE, A. A critica da modernidade. Petrópolis: Editora Vozes, 1999. 